\title{
Editorial
}

\section{Strategic Management and Situational Awareness in Academic Libraries}

This special issue of College $\mathcal{E}$ Research Libraries addresses strategic management in academic libraries. Sounds impressive but what does this mean, really? The literature on strategic management in libraries or even in the management and business literature ranges broadly on this topic. It seems to be full of buzzwords and phrases-like stakeholders and competitive advantage - that are very relevant to a business environment but have no traction in an educational or public service setting. However, jargon aside, there are certainly lessons to be learned. There is no denying that these precepts from the business world are influencing what is going on in higher education and gaining a more strategic understanding of academic librarianship can only help.

For this purpose, the articles herein examine different facets of library management, from performance appraisals to salaries to perceptions of libraries' value. For the variety of topics, they all have one thing in common - they all take into account the evolving trends, changing expectations, and increased accountability affecting higher education and, in turn, academic libraries. The subservience of academic libraries to higher education is deliberate, and while apt to draw a lot of argument, I believe necessary. Academic libraries serve with the endorsement of their parent institutions. As with any discipline, they have their own context and expertise to offer but their very existence is predicated on the institutions they serve. An organization that pays attention to only its own values and priorities is functioning in a vacuum.

There are more than just business practices and tenets impacting academic libraries and their institutions. Factors from every direction seem to be swaying the direction and the expectations of colleges and universities. I have written about these external factors before-because they are indicators of the environment in which academic libraries must succeed, as well as factors that academic libraries, and institutions of higher education more broadly, must acknowledge and learn to navigate. This mindfulness, also called situational awareness, is a matter of their success and, dare I say, their survival.

Situational awareness can be systematized through the use of an environmental scan. Yes, it is another one of those overused industry terms. While it might sound like so much jargon, having a good understanding of the environment in which an organization functions is critical. It is strategic to look at those forces that are at work on higher education. They are a multitude. There are also many frameworks available to consider them - ways in which to do a environmental scan. While the business environment favors SWOT (Strengths-Weaknesses-Opportunities-Threats), I find that using a PEST analysis is quite useful in thinking about the factors influencing a situation. It is a relatively versatile framework that traditionally uses the categories:

- Political

- Economic

- Social

- Technological

It is also not uncommon to see additional factors such as legal or legislative and environmental. This framework is flexible enough to adapt to the context in which it is to be applied. 
While these factors listed above are fairly universal, it can also be adjusted to accommodate a more customer-oriented perspective. Given that academic libraries are very service-oriented organizations and are largely driven by the needs of their constituents, I have reframed this model to be more patron-driven and consistent with a service leadership perspective. In short, the factors driving academic libraries are the faculty and researchers with whom they collaborate; the graduate and undergraduate students they seek to educate and empower; the university administrators from which they derive their mission and vision; the legislators and decision makers to which they are accountable; and the communities they seek to enrich.

The diagram below illustrates the external drivers derived from a PEST analysis through the lens of each of academic library's constituencies. This correlates those groups with environmental factors that affect them and identifies opportunities for academic libraries to engage in a constructive and strategic way.

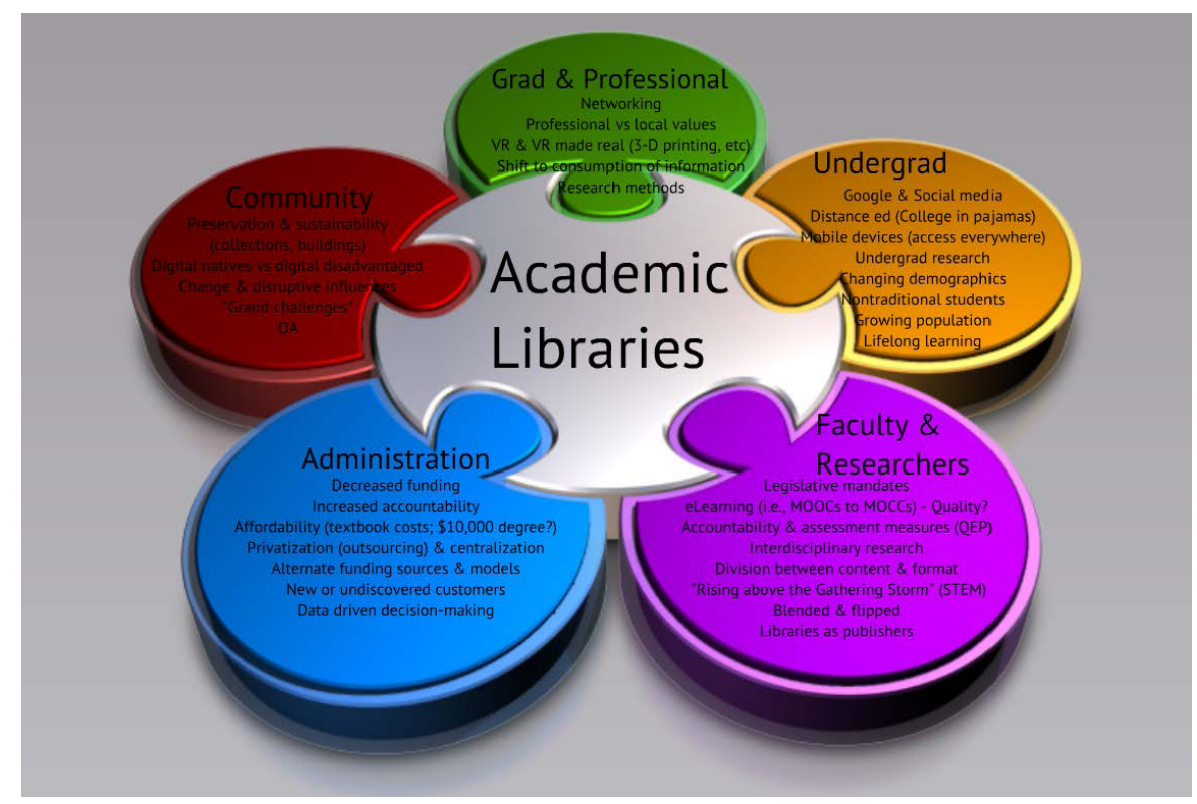

The articles in this special issue are representative of this strategic mindset and provide specific approaches to addressing some of the challenges facing academic librarians and higher education:

They model professional values and ethics.

They advocate for a culture of assessment and accountability.

They investigate issues of social and procedural justice.

They acknowledge the perceptions and influence of decision makers and customers.

They seek ways in which academic libraries can contribute to the education and research mission in higher education.

They understand the importance of communicating library value.

They promote professional education and development that assures high standards of practice.

They are attentive to trends in higher education and innovations.

They provide a panorama of how academic libraries can be thinking about their role, relative to the mission of their institutions and their contribution to society. 